\title{
O ALUNO PÚBLICO ALVO DA EDUCAÇÃO ESPECIAL NO ENSINO MÉDIO: AS RELAÇÕES ENTRE FAMÍLIA E ESCOLA
}

Jéssica Harume Dias Muto

Juliane Ap. de Paula Perez Campos ${ }^{\text {ii }}$

Eleonice Máximo e Melo ${ }^{\mathrm{i}}$

\section{RESUMO}

Este estudo de abordagem qualitativa visa analisar a relação família-escola contando com a participação de quatro mães de alunos Público Alvo da Educação Especial (PAEE) matriculados no ensino médio de uma escola pública do interior do estado de São Paulo. Os dados das entrevistas semi-estruturadas foram analisadas e agrupadas nos eixos temáticos: inclusão; alunos PAEE na escola regular; família e escola; e aluno PAEE no ensino médio. Os resultados apontam a importância de informar às famílias sobre os direitos educacionais que a lei assegura aos alunos PAEE no processo de inclusão no ensino regular; de mudanças na relação família-escola; informar sobre o papel do professor da educação especial dentro da escola às famílias, e sobre as potencialidades e limitações dos alunos PAEE diante da escolarização. Considera-se a necessidade de melhorar a comunicação entre família-escola, propondo-se alternativas que beneficiem essa parceria. Assim, foi evidenciado lacunas para novas pesquisas nessa área.

Palavras-chaves: Educação Especial. Ensino Médio. Família e Escola. Inclusão. 


\begin{abstract}
This qualitative study aims to analyze the family-school relationship with the participation of four mothers of Special Education Students (PAEE) enrolled in high school at a public school in the state of São Paulo. Data from semi-structured interviews were analyzed and grouped into themes: inclusion; PAEE students in regular schools; family and school; PAEE and student in high school. The results show the importance of informing the families about the educational rights that the law provides PAEE students in the process of inclusion in regular education; changes in the family-school relationship; report on the special education teacher's role within the school to families, and on the potential and limitations of PAEE students in front of the school. It considers the need to improve communication between family-school, proposing alternatives that benefit from this partnership. Thus, it was evident gaps for further research in this area.
\end{abstract}

Keywords: Special Education. High school. Family and School. Inclusion. 


\section{INTRODUÇÃO}

A expansão do acesso à escola básica requer mudanças necessárias na formação dos professores, nas políticas, nos currículos, nas condições de trabalho dos profissionais da educação, na infraestrutura das escolas e na reorganização das condições de ensino (GATTI; BARRETTO, 2009). Tais condições são essenciais à melhoria da qualidade da educação para todos os alunos, inclusive para os alunos público alvo da educação especial ${ }^{\text {iii }}$ (PAEE).

Os movimentos em prol da educação inclusiva, dentre outros aspectos, têm como um dos principais focos o acesso, a permanência, e a busca de um ensino de qualidade aos alunos Público Alvo da Educação Especial no ensino regular; uma vez que a maioria das pessoas com deficiência, ao longo da história, foram escolarizadas em instituições especializadas e não tiveram a oportunidade de participar de contextos comuns de ensino.

Sob essa perspectiva, primeiramente o estudo busca contextualizar o aluno PAEE na sociedade e a Educação Especial; o ensino na perspectiva inclusiva; o aluno público alvo da educação especial no ensino médio; e a relação família e escola, e analisar qual a visão da família frente a inclusão desse aluno no ensino regular, destacando-se a etapa do ensino médio e a relação familia e escola.

Ao pensar na história do PAEE na sociedade, a pessoa com deficiência carrega em sua trajetória uma discriminalização em decorrência de fatores sócio-políticoeconômico. Durante séculos ocorreram poucas iniciativas de atendimento educacional ao PAEE, que muitas vezes eram restritas a atendimentos isoladas. A maior parte dos atendimentos que existiam eram de caráter assistencialista, sem a preocupação de escolarizar essas pessoas, mas sim desenvolver aprendizagens ocupacionais e sociais.

A educação como um todo ganha um marco importante em 1988, com a promulgação da Contituição Brasileira na qual atribui-se ao Governo a responsbilidade por garantir o acesso de todos ao ensino, o que antes não acontecia. Segundo Mendes (2010), mesmo que constando no âmbito legislativo, ainda na década de noventa muitas das crianças com deficiências não estavam na escola. Nesse panorama, inclui-se também as pessoas com deficiência no ensino regular (BRASIL, 1988). Contudo, enfrentava-se uma dualidade: matricular em escolas especiais filantrópicas que não tinham a finalidade de escolarizar ou em classes especiais de escolas públicas que apenas tinham o intuito de integrar o PAEE.

Ainda hoje se faz necessário avanços nas práticas políticas para que possamos ver essas pessoas se inter-relacionando dentro de comunidades livres de barreiras atitudinais como preconceito, discriminalização e segregação. Assim, o próximo item contextualiza essa 
relação dentro do contexto educacional em uma perspectiva inclusiva, que é norteada pela Política Nacional de Educação Especial na Perspectiva da Educação Inclusiva reconhecida pelo Ministério da Educação no ano de 2008.

Uma escola inclusiva implica em mudança de atitude diante das diferenças individuais com vista à efetivação do trabalho na diversidade e com o propósito de remover todos os tipos de barreiras que impedem o acesso à aprendizagem e à participação plena da vida em sociedade (CARVALHO, 2004; 2008).

O documento legislativo mais atual, a Política Nacional de Educação Especial na Perspectiva Inclusiva, implementa e reconhece a ação política, cultural, social e pedagógica como movimento mundial pela inclusão no qual defende o direito de todos os alunos estarem aprendendo e participando juntos, considerando a igualdade e diferença como valores indissociáveis (BRASIL, 2008). No entanto, a qualidade no atendimento educacional na escolarização de alunos PAEE na rede regular de ensino ainda está aquém do esperado, principalmente quando se tem um número expressivo de matrículas de alunos incluídos em classes comuns do ensino regular. Conforme o censo escolar (BRASIL, 2014), evidencia-se uma significativa mudança nas matrículas em todas as etapas de ensino, desde a educação infantil até o ensino profissional no período de 2007 a 2013, sendo uma queda de 154 mil matrículas em classes especiais ou instituições especializadas, para um aumento de mais de 342 mil matrículas nas classes comuns nesse mesmo período.

Embora o número de matrículas dos alunos PAEE no ensino regular sinalize um cenário promissor e positivo à inclusão na educação básica, quando destacamos as matrículas da educação especial no contexto do ensino médio encontramos uma realidade bastante diferente comparada ao ensino fundamental.

O ensino médio tem como característica preparar o indivíduo para o trabalho e a cidadania, desenvolver autonomia intelectual e pensamento crítico, consolidados por meio de um ensino que avalie de forma a estimular a iniciativa do aluno, para que este mostre domínio dos princípios científicos-tecnológicos, da linguagem, filosófico e sociológico (BRASIL, 1996). Enquanto a organização pedagógica deve possibilitar ao aluno desenvolver uma identidade como adolescente, jovem ou adulto, respeitando as suas condições e necessidades de espaço e tempo para a aprendizagem (BRASIL, 2012).

Muitos jovens, no entanto, abandonam esse nível de ensino como mostra o Censo Escolar (INEP, 2014) que há 29 milhões de matrículas no ensino fundamental e somente 8 milhões no ensino médio regular. Quando observamos as matrículas da Educação Especial nesses dois níveis de ensino, a realidade é a mesma, em que 623 mil alunos estavam 
matriculados no ensino fundamental, considerando as classes especiais e as classes comuns, e somente 48 mil estavam matriculados no ensino médio. (INEP, 2014).

A evasão escolar é discutida no estudo de Souza et al. (2011) que trazem duas vertentes da evasão: os fatores externos, considerados aqueles relacionados principalmente com a desigualdade social, como a necessidade de trabalhar para ajudar a família, o ingresso na criminalidade e violência e os problemas familiares; e os fatores internos, aqueles ligados diretamente à escola, ou seja, a gestão escolar, os alunos, os professores, a comunicação dentro dessa comunidade e as políticas de governo que norteiam a educação básica podem estar relacionadas diretamente à evasão escolar dos alunos.

Outros fatores que podem ocasionar a evasão escolar é o fracasso e a repetência escolar que pode estar relacionados com uma inapropriada adequação da realidade à dos seus alunos e, portanto, nao ser atrativo quanto a forma de abordar temas relacionados aos seus contextos regionais e culturais (MOURA; SILVA, 2005). A respeito disso PATTTO (1992) considera que o modelo de ensino massificante no qual o aluno é induzido apenas a reproduzir conceitos e ideias e que tem por finalidade principal possibilitar o ingresso em instituições de ensino superior, técnino ou no mercado de trabalho, não considerando as particularidades dos alunos e, por conseguinte, não respeitando a heterogeneidade da comunidade nesses ambientes.

O aluno PAEE pode encontrar maiores barreiras dentro do sistema de ensino, dentre outros aspectos, pelo desconhecimento do professor diante das necessidades educacionais especiais. Outros fatores prováveis que contribuem para essa discrepância no número de alunos PAEE incluídos no ensino médio pode-se destacar as fragilidades nas políticas públicas quanto a inclusão desses no ensino médio e a desmotivação da família frente à inclusão desses alunos. Neste sentido, o processo de inclusão e permanência escolar envolve a participação de diversos agentes educacionais, sendo que um dos maiores desafios refere-se às relações entre a família dos alunos PAEE incluídos no ensino médio e a escola.

A relação entre a família e a escola tem se caracterizado por ser um fenômeno pouco harmonioso e satisfatório, uma vez que as expectativas de cada instituição ou de cada ator envolvido não são atendidas e se mostram pouco favoráveis ao crescimento e desenvolvimento dos alunos. Ainda, para que este desafio seja superado é necessário o desenvolvimento de pesquisas que invistam no conhecimento da relação família-escola (OLIVEIRA; BISINOTO; MARINHO-ARAÚJO, 2010).

Essa inter-relação deve ser promovida de modo que a escola e a família mantenham uma parceria com o intuito comum de encontrarem recursos que favoreçam 
condições que maximizem o desenvolvimento escolar do aluno. Isso se torna real quando a escola viabiliza uma participação da família dentro do contexto escolar, seja em processos de ensino e aprendizagem ou de organização e gestão escolar (CAMPOREZI; KUHN, 2014; CASTRO; REGATTIERI, 2009; POLÔNIA; DESSEN, 2005; SOUZA; JOSÉ FILHO, 2008).

Considerando estudos que contemplam famílias de alunos PAEE, foram localizados o estudo de Christovam e Cia (2013) que verificou a percepção de pais de crianças incluídas em idade pré-escolar e professores sobre a relação família-escola e o de Borges, Gualda e Cia (2015) que descreveu a relação entre a família de crianças pré-escolares público alvo da educação especial, segundo a opinião de professores, notando-se que a boa relação entre pais e professores ocorrem por meio de diálogos, interesse e participação da família na escola e pela continuidade dos trabalhos da escola em outros ambientes.

Sendo assim, sabendo-se da importância da participaçao da família durante todo o processo escolar da criança é, portanto, imprescindível edificar uma parceria entre família e escola com o propósito único de propiciar condições favoráveis que visem garantir e maximizar o processo de aprendizagem dos alunos, sendo ou não PAEE. De maneira geral, essa temática exige uma profunda análise a fim de melhor compreender como são estabelecidas as relações entre a família e escola.

Essa realidade e necessidade impulsionaram o interesse em pesquisar como se estabelece esse vínculo, tomando como objeto de estudo a perspectiva da família de alunos PAEE em relação ao ensino médio da escola regular. Questionar sobre como se estabelece a relação família/escola, sob a ótica dos pais, e como esses pais percebem a escola em relação à escolarização de seus filhos com deficência no ensino médio são elementos chaves necessários para a análise e entendimento dessa temática. Portanto, neste estudo em específico, busca-se compreender apenas a perspectiva da família em relação a essa parceria família-escola.

Assim, identificado que a família é fundamental para o processo escolar da criança e que a mesma necessita ter uma relação com a escola para que ao formarem-se como parceiros com o mesmo objetivo a ser alcançado e que deste modo busquem o sucesso do processo educacional do aluno, seja alunos PAEE ou não, é necessário uma análise e compreensão de como acontece essa parceria, de que modo se dão as relações da família e a escola, na perspectiva dos pais, e como a família percebe a escola, frente à escolarização de seu filho PAEE no ensino médio. Ao identificar se há ou não uma parceria, compreender de ambos os lados é necessário para que identifique-se se está de fato ocorrendo uma parceria, 
quais são suas dificuldades e facilidades, ou se meramente ocorre uma atuação independente de ambas instituições. Neste estudo em específico, busca-se compreender apenas a perspectiva da família em relação a essa parceria família-escola.

O presente estudo teve como objetivo compreender as relações entre as famílias de alunos PAEE e a escola de ensino médio, segundo a visão da família, e para que o objetivo geral fosse alcançado, o estudo contemplou os seguintes objetivos específicos: a) identificar as situações e ações descritas pela família que caracterizam as relações entre a família e a escola; b) analisar como a família percebe a escola frente à escolarização do filho PAEE; e c) identificar a expectativa familiar quanto ao futuro PAEE.

\section{MÉTODO}

Este estudo teve como referência metodológica a abordagem qualitativa, como pesquisa exploratória-descritiva (GIL, 2008).

Após a aprovação do comitê de ética, a pesquisadora iniciou a busca pelos participantes através de uma consulta com responsável do setor da educação especial na secretaria estadual da educação do município, para que pudesse assim, obter informações de onde encontram-se os alunos público alvo da pesquisa.

Diante disso, foi escolhida uma instituição de ensino do município em que haviam o maior número de matrículas de alunos PAEE no ensino médio. A pesquisadora entrou em contato com o coordenador pedagógico do ensino médio dessa instituição convidando-o a participar da pesquisa; autorizado, foi solicitado que a instituição entrasse em contato com os familiares de alunos PAEE matriculados no ensino médio.

Participaram do estudo quatro familiares de alunos PAEE matriculados no ensino médio, seguindo os critérios de seleção: a) Possuir parentesco com o aluno Público Alvo da Educação Especial; e b) sendo este matriculado no ensino médio da rede pública de ensino.

Tabela I - Caracterização dos entrevistados - Familiares

\begin{tabular}{c|c|c|c|c|c|c}
\hline Participante & Idade & $\begin{array}{c}\text { Estado } \\
\text { civil }\end{array}$ & $\begin{array}{c}\text { Nível de } \\
\text { Escolaridade }\end{array}$ & $\begin{array}{c}\text { Vínculo } \\
\text { Empregatício }\end{array}$ & $\begin{array}{c}\text { Outros } \\
\text { filhos }\end{array}$ & Parentesco \\
\hline P1 & 44 & Casada & $\begin{array}{c}\text { Ens. } \\
\text { Fundamental } \\
\text { Incompleto }\end{array}$ & Não & Sim & Mãe \\
\hline P2 & 42 & Casada & $\begin{array}{c}\text { Ensino } \\
\text { Fundamental } \\
\text { Completo }\end{array}$ & Não & Sim & Mãe \\
\hline P3 & 36 & Divorciada & $\begin{array}{c}\text { Ensino Médio } \\
\text { Completo }\end{array}$ & Sim & Não & Mãe \\
\hline P4 & 47 & Casada & $\begin{array}{c}\text { Ensino } \\
\text { Fundamental } \\
\text { Incompleto }\end{array}$ & Não & Sim & Mãe \\
\hline
\end{tabular}


Os quatro participantes entrevistados (Tabela I) eram mães dos alunos. A idade média dessas mães é de 42 anos; o nível de escolaridade variou de ensino fundamental incompleto ao ensino médio completo; três mães não possuíam vínculo empregatício e três disseram ter outros filhos além do aluno da pesquisa.

Tabela II - Caracterização dos alunos no Ensino Médio

\begin{tabular}{c|c|c|c|c}
\hline Aluno & Idade & Escolaridade & Diagnóstico & Congênita ou Adquirida \\
\hline P1/João* & 15 & $1^{\circ}$ ano & Mielomeningocele & Congênita \\
\hline P2/Ana* & 21 & $1^{\circ}$ ano & Paralisia Cerebral & Congênita \\
\hline P3/Paula* & 16 & $1^{\circ}$ ano & $\begin{array}{c}\text { Baixa Visão; Baixa Audição e } \\
\text { Deficiência Intelectual }\end{array}$ \\
\hline P4/Murilo* & 15 & $1^{\circ}$ ano & Síndrome de Williams & Congênita \\
\hline
\end{tabular}

*Os nomes utilizados para identificar os alunos são fictícios.

Os alunos selecionados como critério de participação dos familiares (Tabela II) estavam matriculados no primeiro ano do ensino médio coincidentemente, com idade média de 16 anos; todos com deficiência congênita que variou de síndrome a deficiência múltipla; somente um aluno não havia estudado em instituição especial.

A coleta dos dados ocorreu na instituição de ensino e também na residência do participante. Ambos os locais estão situados em um bairro periférico de uma cidade de médio porte do interior do estado de São Paulo.

Para a realização desse estudo utilizou-se canetas, lápis e papéis, e os equipamentos utilizados foram um aplicativo de gravador de vOz em um smarthphone, impressora e computador.

No estudo, utilizou-se uma ficha de identificação do entrevistado e do aluno, um formulário socioeconômico e um roteiro de entrevista semi-estruturado contendo 17 questões, com o objetivo de conhecer, na visão das famílias, as ações e comportamentos da família junto à escola, e vice-versa, de modo a compreender as relações entre família e escola; assim como as percepções dos entrevistados sobre a escolarização do filho no ensino médio.

A duração da entrevistas foi de aproximadamente 25 minutos de duração, na instituição em que os alunos PAEE estavam matriculados com data e horário que melhor atendesse a família, com exceção de uma mãe a qual por motivos particulares solicitou que fosse realizada em sua residência.

Os dados coletados por meio da entrevista semi-estruturada foram analisados de forma qualitativa, buscando compreender as relações entre as famílias de alunos PAEE e a escola de ensino médio, segundo a perspectiva da família.

A gravação das entrevistas foi transcrita e categorizada em quatro eixos temáticos para que dessa forma proporcionasse uma observação mais detalhada da visão 
familiar sobre determinado assunto. Foram categorizados em: a) Inclusão: apresenta qual a visão da família diante da inclusão de seu filho em uma instituição de ensino regular, buscando compreender o que a família entende e se ela é favorável à esse processo inclusivo; b) Alunos público alvo da educacão especial na escola regular: traz questões relacionadas ao aluno estar matriculado em uma instituição de ensino regular, ou seja, se o ensino alcança à demanda do aluno diante da visão familiar, se há um atendimento da educação especial e como é a relação com os profissionais da escola; c) Família e escola: busca compreender se há contato da família do aluno PAEE com a equipe escolar, como e com qual frequência se dá esse contato; a compreensão da família sobre o aprendizado do seu filho e a metodologia de ensino utilizada; e como esse se comporta dentro do ambiente Famíliar e escolar; e d) Aluno público alvo da educação especial no Ensino Médio: busca conhecer qual a perspectivia da família diante do aluno PAEE estar matriculado no ensino médio e quais as expectativas após o término desse módulo de ensino.

\section{RESULTADOS E DISCUSSÃO}

Os dados obtidos nas entrevistas foram agrupados em quatro eixos temáticos, sendo os resultados apresentados a seguir:

\section{$\underline{\text { Inclusão }}$}

Em relação ao tema inclusão, foram questionados aos participantes o que compreendiam, em sua perspectiva, a palavra inclusão; se a escola onde seu filho está matriculado cumpre com a proposta de inclusão e se é favorável a essa inclusão. Das quatro mães, apenas uma relatou não saber o que era inclusão, e diante disso não foi possível responder as questões desse eixo temático. P2 relatou que a inclusão é uma oportunidade à pessoa com deficiência; P3 e P4 entendem inclusão como a matrícula de pessoa com deficiência em uma escola regular de ensino recebendo o mesmo atendimento educacional das pessoas consideradas "normais".

A educação inclusiva é um novo modelo de escola em que o acesso e a permanência de todos os alunos, independente de suas condições socioeconômicas, raciais, culturais ou de desenvolvimento é possível, identificando e removendo barreiras para a aprendizagem substituindo os mecanismos de seleção e discriminação, necessitando de formação de professores e equipe de gestão, estruturação e organização no projeto políticopedagógico, nos recursos didáticos, metodologias, estratégias e avaliação de ensino; a Educação Inclusiva é uma nova cultura escolar que traz uma concepção de escola que visa o 
desenvolvimento de respostas educativas que atinjam a todos os alunos (GLAT; BLANCO, 2007).

Justifica-se o fato de uma possível variação nas perspectivas das mães diante desse tema, dado que 75\% dos participantes que definiram inclusão, disseram ser a favor desse movimento nas escolas, pois incluir o aluno PAEE na escola junto aos outros alunos "normais" favorece em seu desenvolvimento social e cognitivo. Entretanto, P2 ressalta que ainda falta um suporte ao aluno o qual dê estabilidade para seu aprendizado, justificando que “já que é uma inclusão tem que oferecer uma estabilidade para o aluno. [...] não só estar incluso na escola, [...] só para vir e dizer que está participando da inclusão [...] - (P2)” e a mãe justifica que a falta desse suporte decorre por ser uma escola estadual.

Contudo, $50 \%$ dos participantes afirmaram constatar significantes progressos na aprendizagem de seus filhos, pois a letra melhorou e adquiriu a leitura; P3 ressalta ainda que os materiais adaptados fornecidos pela escola para a aluna com baixa visão foram fundamentais para o seu desenvolvimento escolar.

É importante ressaltar que o aluno pode demandar, além de recusos alternativos para acessar o conteúdo, o aluno pode necessitar de alternativas para se comunicar, o que é essencial para o processo de ensino e aprendizagem.

\section{Alunos público alvo da educação especial na escola regular}

Segundo os relatos de P2 e P4 não há uma prática inclusiva, pois seus filhos não conseguem acompanhar o ritmo da sala de aula decorrente das limitações que suas deficiências, física e intelectual e essa limitação ocasiona à prática de atividades diferentes dos demais alunos, ou seja, contrapõe-se a LDB nº 9.394/96.

Um dos aspectos que podem beneficiar a heterogenidade em sala de aula é realizar a adequação curricular, entendida como uma estratégica didático-metodológica que permite aos alunos com significativas dificuldades em aprendizagens de conteúdos acadêmicos a beneficiar-se do currículo ${ }^{\text {iv }}$ (LEITE et al., 2011), como os alunos PAEE. O que não acontece com os alunos desse estudo, como visto anteriormente. A única estratégia existente frente ao acesso ao currículo é o caso da aluna Paula, que recebe livros com fonte maiores e lupa para auxiliar na leitura dos conteúdos.

Pressupõe-se que essa falta de inclusão escolar pode ocorrer devido à dificuldade do professor em lidar com o aluno PAEE na sala regular de ensino; pela falta de formação e informação desse professor (GUADAGNINI; DUARTE, 2013); e essa prática influencia diretamente na aprendizagem do aluno, pois sendo o professor uma figura 
mediadora de conhecimento deve transmitir isso a todos. Assim, o ensino tradicional massificante deve ser substituído por um ensino que atenda à diversidade (FIGUEIREDO, 2008).

Mesmo que a taxa de matrícula dos alunos PAEE nas escolas regulares de ensino apresentem um aumento significativamente, muitas vezes tanto o professor que trabalha diretamente com esse aluno como a gestão escolar que tem o contato com a família, não tem conhecimentos sobre a escolarização e o atendimento educacional ao aluno PAEE. Frente a isso, Mendes, Almeida e Toyoda (2011) destacam em seu estudo a importância de pesquisas na perspectiva da educação inclusivas e a parceria das universidades em colaborar com as escolas da rede regular com o fornecimento de conhecimentos especializados nessa área, qualificando seus trabalhos frente a uma nova demanda social. E ainda, comprovam que o aluno PAEE beneficia-se diante de novas atitudes dos professores e dos colegas de sala com o desenvolvimento típico, mediante ao novo aprendizado sobre o projeto de inclusão nas escolas.

É necessário não somente que os professores, que já estão atuando com esses alunos, busquem conhecimentos sobre educação inclusiva, mas que também contribuam para uma mudança na formação desses. Hoje, os cursos de licenciaturas e pedagogia tem a obrigatoriedade de oferecer o ensino de Língua Brasileira de Sinais (LIBRAS), que atende ao aluno surdo especificamente, como estabelecido pelo Decreto $n^{\circ}$ 5.626/05 (BRASIL, 2005). Há uma necessidade no conhecimento prévio sobre todos os alunos PAEE durante a formação acadêmica, e conforme a demanda da prática, é necessário que esse professor aperfeiçoe seus conhecimentos acerca de estratégias e metodologias de ensino e sobre especificidades do desenvolvimento de seu aluno PAEE.

Diante das falas das mães, observou-se uma concordância na garantia do aprendizado de seus filhos, mesmo os alunos não acompanhando as atividades que os professores passam na lousa como relataram as mães. Então o que seria de fato essa garantia de aprendizado para as mães? P4 afirma que essa garantia do aprendizado justifica-se nas atividades diferentes passadas em seu caderno separadamente do conteúdo da turma, mas disse que não se "preocupar muito", porque os médicos já informaram que ele, em decorrência da síndrome de Willians, que apresenta como característica a deficiência intelectual, pode ou não aprender conteúdos escolares. Para essas mães, a garantia de aprendizado talvez esteja associada à matrícula desses alunos na escola regular. Castro e Regattieri (2009) apontam que há estudos que mostram que parte dos pais de alunos de escolas públicas confundem o dirieto à educação com a vaga na escola, o que na verdade, 
esse direito refere-se ao pleno desenvolvimento como pessoa, preparando-o para o exercício da cidadania e qualificando-o para o trabalho, advindo da aprendizagem recebida na escola e na família, pois a família tem o direito e responsabilidade no processo pedagógico de seu filho (BRASIL, 1990).

Essas dificuldades na aprendizagem dos alunos, pode decorrer da falta de conhecimento dos professores regente em sala de aula.

$\mathrm{Na}$ entrevista apenas uma mãe disse não haver atendimento da educação especial com seu filho, no entanto a escola fornece esse atendimento ao aluno através do projeto PIBID, o qual é realizado por um aluno do curso de Licenciatura em Educação Especial realizando um trabalho colaborativo com o professor da sala regular.

Diante disso, é questionável a importância da relação família-escola como meio de conhecimento dos atendimentos do aluno PAEE, seus direitos e desenvolvimento escolar. No ensino público há uma fragilidade nessa inter-relação advindo de um contexto social histórico, pois a família não tem a cultura de exigir uma educação de qualidade, confundido-a com a vaga na escola, com o transporte escolar, com o uniforme e a merenda escolar, e a escola se vê como um local onde há profissionais da educação que recebem formação sobre os direitos e deveres de uma intituição de ensino básico o qual deve promover metas educacionais, o acesso ao projeto pedagógico, e o papel que a família tem na educação de uma criança ou adolescente (CASTRO; REGATTIERI, 2009). A escola necessita dar voz à família de modo mais lúdico, com técnicas que permita a família sentirse mais acolhida e poder expressar seus pontos de vista sobre a escolarização.

Quando questionado aos participantes sobre a relação de seus filhos com os professores, coordenadores e demais funcionários da escola, 25\% disseram não ter conhecimento sobre essa relação. Dentre os $75 \%$ dos participantes que disseram ter uma boa relação, P1 e P4 citaram o bom contato com todos e P3 explica que o filho somente tem contato com a professora. P4 quando cita esse contato com todos, justifica essa relação como sendo boa por ser uma característica da Síndrome de Williams que seu filho apresenta: comportamento amigável e altamente social mesmo com pessoas desconhecidas (TOBIASMACHADO et al, 1998).

O desconhecimento das mães diante da qualidade dessa relação, faz-nos questionar a falta de informação sobre os acontecimentos dentro do ambiente escolar. Os gestores têm uma função fundamental para essa relação família-escola, um papel de aproximar professores, familiares, conselheiros escolares, grêmios estudantis e outros segmentos que compõe a escola e a comunidade local para transparecer, debater e consolidar 
ideias do processo educacional democrático (GRACINDO, 2009); assim, consolida-se numa visão mais participativa a evolução na qualidade de ensino público e os conhecimentos e participação familiar no processo de desenvolvimento escolar de seu filho.

A qualidade fica a desejar como observado na pesquisa de Patto (1992) sobre o fracasso e repetência escolar, por isso é importante a participação de outros membros, principalmente a família, para se discutir a qualidade do ensino público. Porém, como já discutido a problemática da permanência escolar, como ficaria o aluno PAEE frente as dificuldades do acesso ao ensino? Esses alunos chegariam ao final do ensino médio? Se concluirem, o que farão após o término do ensino básico obrigatório?

Já discutimos que a fragilidade no ensino influência para a evasão escolar, mas e o preconceito frente à pessoa fora do padrão socialmente estabelecido, será que isso ainda ocorre na inclusão escolar, podendo influenciar a permanência do aluno PAEE na escola? Quando questionadas sobre preconceito dentro do ambiente escolar, 75\% das mães, disseram já ter ocorrido algum tipo de preconceito. A paricipante P4 relatou que seu filho é chamado de "boca aberta" e "magrelo" pelas características físicas típicas da Síndrome de Williams, e P3 diz que os colegas de sala não aproximam-se de sua filha por que não gostam do mesmo assunto destacando-se em sua fala:

(...) ela reclama, ela fala que eles não a conhecem. Porque as meninas não conhecem os problemas dela, então ela começa a conversar de boneca, e qual a menina de 16 anos que vai falar de boneca? Umas são até mães! Tem uma na sala dela mesmo que já é mãe, tem um bebê! Então elas não querem falar de boneca, e a Paula quer falar de boneca, de desenho, de Cavaleiros do zodíaco, é isso! A conversa, o ciclo da Paula é isso! Ela não tem uma conversa construtiva. [...] Então eu entendo as meninas, as meninas não querem saber disso, elas querem falar de beijinho, de menininho e não sei o que, e ela não, ela quer falar de boneca. Ela não tem amizade fora, ela não tem amigos, ela não tem amigos que vão até a minha casa. [...] Porque até o meu sobrinho, que sabe dos problemas dela que convive na minha casa e estudou com ela no ano passado vivia chacotando ela, tirando o sarro dela! Então é ela por ela! (P3).

Os resultados apresentados não representam um caso isolado. Estudos mostram que o preconceito está presente na relação aluno-aluno PAEE e do professor-aluno PAEE (BATISTA; ENUMO, 2004; CROCHÍK et al., 2011; OLIVA, 2011; SHIMONO, 2008). Com o movimento de inclusão escolar, é necessário que estratégias sejam realizadas diante desse novo processo. Mostra-se necessário a busca por conhecimentos que promovam a melhor inclusão e permanência dos aluno PAEE na escola.

\section{$\underline{\text { Família e escola }}$}


A relação entre família e escola deve ser um caminho de duas direções em que ambas possam trocar informações que contribuam para o desenvolvimento da criança ou adolescente, de modo nessa relação não estabeleça a responsabilidade do desenvolvimento do aluno para somente uma das partes.

A escola é um ambiente com a função de promover a aquisição de ciência e instrumentos que possibilitem esse conhecimento avançado (OLIVEIRA; BISINOTO; MARINHO-ARAUJO, 2010). Já o contexto familiar constitui-se como o primeiro ambiente de relações sociais de um indivíduo, onde se proporciona o crescimento e o desenvolvimento (SILVA; DESSEN, 2001). Os pais de alunos PAE, diante do diagnóstico, muitas vezes se deparam com um luto por seu filho não corresponder àquele idealizado, de forma a só enxergar seu filho como um ser incapaz de se desenvolver. Neste sentido, o despreparo do médico para informar aos pais sobre o diagnótisco da criança e a ressalva nos aspectos de déficits, traz inúmeras consequências no estímulo social que essa criança necessita para se desenvolver. Como demostrado na fala da $\mathrm{P} 4$, quando diz não se preocupar com a aprendizagem de seu filho, influenciada pela fala médica. Diante dessa falta de preparo dos profissionais da saúde, o momento da escolarização torna-se importante, pois a escola preparada para estimular o desenvolvimento do PAEE, potencializa e mostrar à família as possibilidades no desenvolvimento desse aluno.

Mas, será que a escola sempre está pronta para receber a família dos alunos? $75 \%$ dos participantes afirmaram que a escola sempre está pronta para recebê-los, mas essa relação está restrita somente aos dias de reuniões ou no horário de entrada ou saída dos alunos. Somente uma participante negou haver uma parceria existente entre a família e a escola, justificado pela circunstância da filha ter ingressado no início do ano nessa escola na qual a pesquisa foi realizada.

\section{Aluno público alvo da educação especial no Ensino Médio}

Quando indagado às mães sobre a expectativa do filho estar matriculado no ensino médio, $50 \%$ dessas não acreditavam que o filho chegaria a esta etapa do ensino diante das dificuldades relacionadas à deficiência. Entretanto, é promissor que esses estejam matriculados no ensino médio diante das dificuldades da inclusão escolar, por isso é necessário que medidas sejam tomadas para que esses alunos não abandonem os estudos e concluem aprendendo de fato os conteúdos do currículo.

Quando o aluno se depara com dificuldades de ensino, repetência e má qualidade de infraestrutura educacional, ele passa a acreditar que a escola não contribuirá 
para um futuro melhor dentro de sua realidade e deixa de frequentar a escola. Mas, há também casos em que o aluno tem vontade de ir à escola e a família incentiva continuar os estudos, como expressado na fala de P3 e P4:

Eu achei que quando ela completasse a oitava série ela não fosse, tipo ela não quisesse mais ir para a escola. Mas ela está vindo, ela está bem, ela fala em faculdade. Ela fala dessas coisas, ela fala que quer fazer um curso de desenho [...]" - P3.

(...) eu cheguei a falar que eu iria abandonar tudo, porque eu pensava assim: "ah, acho que é melhor tirar da escola, deixar ele em casa sem fazer nada, porque não adianta, não vai em frente [...]. Mas, hoje eu vejo que o que ele faz é esforçado, por tudo. No lugar que ele pede que quer, que quer fazer atividade, largo tudo, largo por mim para ir para ele- $\mathrm{P} 4$.

Ao final da entrevista foi permitido aos participantes expressarem livre e expontaneamente sobre suas expectativas e sugestões a respeito da relação entre família e escola e a inclusão dos alunos PAEE no ensino regular. A entrevistada P3 sugeriu uma participação maior dos pais na escola, de modo que transmitam mais o que acontece dentro do ambiente escolar com sua filha, um pedido para que a escola proponha encontros e assim conversem sobre o desenvolvimento da adolescente. Já P4 fez uma sugestão de incluir um professor que auxilie a professora nas atividades dentro de sala de aula para o aluno com Necessidades Educacionais Especiais, ou seja, um professor da Educação Especial.

Essas expectativa e sugestão expressam o cenário da realidade de alguns dos problemas que envolvem o processo de inclusão na escola regular e que podem, também, contribuir diretamente para o aumento do número de evasão escolar. Faz-se necessário uma receceptividade mais ativa por parte da gestão escolar favorecendo a aproximação dos pais, estimulando diálogos para ouvir seus interesses, trocar informações e planejar estratégias de melhorias do processo educativo e inclusivo. Essas são algumas das condições indispensáveis para se estabelecer e/ou fortalecer uma relação de parceria entre escola e família. Fica evidente, também, que os pais compreendem a necessidade e importância da efetiva participação do professor de Educação Especial atuando em conjunto com o professor da sala aula comum. 


\section{CONSIDERAÇÕES FINAIS}

Considerando os aspectos de cada eixo temático abordado no estudo, foi possível constatar que a ausência de informações sobre os direitos educacionais aos alunos PAEE neutraliza o poder de os pais de reivindicarem por melhorias no processo de inclusão do Ensino Regular.

Destaca-se necessidade de informar às famílias dos alunos público alvo da educação especial quais são os direitos garantidos por lei em âmbito educacional para seu filho diante do processo de inclusão em instituição de ensino regular. Esse conhecimento favoreceria a família de tal modo a colaborar ativamente no processo de ensino do filho, entretanto a escola teria o papel fundamental de tornar possível essa parceria entre familia e escola.

Neste sentido, há a necessidade de mudança em relação ao contato entre família e escola, propondo-se alternativas de comunicação com a família, e não somente em reuniões como acontece, mas um dia da semana com horário livre com o professor responsável pela turma do aluno ou com o coordenador, de forma que relate os fatos acontecidos na aprendizagem do aluno e suas dificuldades também, afinal a família pode auxiliar em métodos ou estratégias que beneficie o aprendizado do aluno pela família ser uma extensão da escola. Essas mudanças proporcionaria uma aprendizagem mais rica e funcional para aos alunos, favorecendo seu desenvolvimento cognitivo e social.

O ensino de qualidade a todos no Brasil ainda é algo a ser alcançado e a educação inclusiva ainda é um desafio. As escolas necessitam de mais informações políticas e educacionais diante de um aluno PAEE. É necessário que a gestão frente a essa nova perspectiva de acesso à educação para todos, busque modificar suas ações frente a comunicação com as famílias, sendo essas de alunos PAEE ou não; a escola necessita dar mais espaço a diálogos entre profissionais da educação ou demais áreas, se necessário, discutindo novas metodologias de abordar a educação para crianças e jovens, que torne-se mais atrativas aos alunos e familiares, que seja um ambiente onde discutam-se progressos e desafios da escolarização de alunos, principalmente jovens PAEE.

Outro aspecto de grande relevância é o papel da educação especial em parceria com o professor regente da sala comum, pois há uma falta de conhecimento sobre as potencialidades e limitações dos alunos público alvo da educação especial. E a inclusão do professor da educação especial na escola pode auxiliar a equipe escolar a ter um outro olhar diante das demandas dos alunos e das famílias. Uma vez que o professor na sala de aula comum passa a atentar-se nas necessidades dos alunos e reconhece uma mudança, ele pode 
apresentar trabalhos de modos heterogêneos com o mesmo objetivo; a mudança de metodologias e a dinâmica do ensino é de grande importância para todos os alunos.

Vale ressaltar que este estudo não teve a pretensão de esgotar o tema da relação escola/família, mas ao contrário, corroborar a necessidade de se investir em novas pesquisas nessa área, sob diferentes perspectivas.

Diante desse cenário, é notório a importância de novos estudos sobre essa temática para uma compreensão mais apurada dos fatores envolvidos na dinâmica dessa relação escola/família. Sendo assim, apropriar-se desses conhecimentos beneficiará o sistema educativo como um todo e, consequentemente, favorecerá significativamente o processo de inclusão nas instituições de Ensino Regular. 


\section{REFERÊNCIAS}

BATISTA, M. W.; ENUMO, S. R. F. Inclusão escolar e deficiência mental: análise da interação social entre companheiros, Estudos de Psicologia, v. 9, n. 1, p. 101-111. 2004.

BORGES, L.; GUALDA, D. S.; CIA, F. Relação Família e Escola e Educação Especial: opinião de professores, Educação: Teoria e Prática, Rio Claro, Vol. 25, nº. 48, p. 168185, Jan-Abr. 2015.

BRASIL, Constituição da República Federativa do Brasil de 1988. Brasília: Imprensa Oficial, 1988. Disponível em:

<http://www.planalto.gov.br/ccivil_03/constituicao/constituicao.htm>. Acesso em: jul. 2015.

Lei $\mathbf{n}^{\mathbf{0}} \mathbf{8 . 0 6 9}$, de 13 de Junho de 1990, Estatuto da Criança e do Adolescente, 1990. Disponível em: < http://www.planalto.gov.br/ccivil_03/LEIS/L8069.htm>. Acesso em: jul. 2015.

Lei n. $^{\mathbf{0}} \mathbf{9 . 3 9 4}$, de 20 de Dezembro de 1996. Estabelece as diretrizes e Bases da educação nacional. Disponível em: < http://www.planalto.gov.br/CCIVIL_03/leis/L9394.htm>. Acesso em: jul. 2015.

Decreto $\mathbf{n}^{\mathbf{0}}$ 5.626, de 22 de dezembro de 2005, Língua Brasileira de Sinais (Libras), Brasília, DF, 2005. Disponível em: < http://www.planalto.gov.br/ccivil_03/_ato20042006/2005/decreto/d5626.htm>. Acesso em: jul. 2015.

Política Nacional de Educação Especial na Perspectiva da Educação

Inclusiva, Ministério da Educação. Secretaria de Educação Especial. Brasilia: MEC/SEESP, 2008.

Diretrizes Curriculares Nacionais para o Ensino Médio resolução n ${ }^{\mathbf{0}}$ 2, de 30 de Janeiro de 2012, Conselho Nacional de Educação, Brasília: Ministério da Educação, 2012.

Censo da educação básica 2013: resumo técnico, Brasília: Instituto Nacional de Estudos e Pesquisas Educacionais Anísio Teixeira, 2014.

CAMPOREZI, E.V.; KUHN, A. P. A participação da família na aprendizagem das crianças: um estudo de caso no $3^{\circ}$ ano do ensino fundamental, Revista da Universidade Vale do Rio Verde, Três Corações, v. 12, n. 1, p. 834-854, jan./jul. 2014.

CARVALHO, R. E. Educação Inclusiva: com os pingos nos "is". Porto Alegre: Mediação, 2004.

Escola Inclusiva: a reorganização do trabalho pedagógico. Porto Alegre: Mediação, 2008.

CASTRO, J. M.; REGATTIERI, M. Interação escola-família: subsídios para práticas escolares. Brasília: UNESCO/MEC, 2009.

CROCHÍK, J. L. et al. análise de atitudes de professores do ensino fundamental no que se refere à educação inclusiva, Educação e Pesquisa, São Paulo, v. 37, n. 3, p. 565-582. 2011. 
CHRISTOVAM, A. C. C.; CIA, F. O Envolvimento parental na visão de pais e professores de alunos com necessidades educacionais especiais. Revista brasileira de educação especial, Marília, v.19, n. 4, p. 563-581. 2013.

FIGUEIREDO, R. V. A formação de professores para a inclusão dos alunos no espaço pedagógico da diversidade. In: Maria Tereza Eglér Mantoan (Orgs.). O desafio das diferenças nas escolas. 1 ed. v. 1. Petrópolis: Vozes, p. 141-145. 2008.

GATTI, B. A.; BARRETO, E. S. de S. Professores do Brasil: impasses e desafios. Brasília: UNESCO, 2009.

GIL, A. C. Como elaborar projetos de pesquisa. 4.ed. São Paulo: Atlas, 2008.

GLAT, R.; BLANCO, L. M. V. Educação Especial no contexto de uma Educação Inclusiva. In: GLAT, R. (Orgs.). Educação inclusiva: cultura e cotidiano escolar. Rio de Janeiro: Editora 7Letras, 2007.

GUADAGNINI, L.; DUARTE, M. Práticas Pedagógicas de Acessibilidade Curricular para Alunos com Deficiência Intelectual em Classes do ensino Fundamental e Médio. VII

Congresso Brasileiro Multidisciplinar de Educação Especial, p. 3769 - 3779. 2013.

GRACINDO, R. V. O gestor escolar e as demandas da gestão democrática: Exigências, práticas, perfil e formação, Revista Retratos da Escola, Brasília, v. 3, n. 4, p. 135-147. 2009.

LEITE, L. P. et al. A adequação curricular como facilitadora da educação inclusiva, Psicologia da Educação, São Paulo, 32, p. 89-111, 2011.

LIBÂNEO, J. C. O planejamento escolar e o projeto pedagógico-curricular. In:

Organização e Gestão da Escola: teorias e práticas. São Paulo: Heccus editora, 2013. p.125-165.

MENDES, E. G. Breve histórico da educação especial no Brasil, Revista Educación y Pedagogia, vol. 22, núm. 27, 2010.

MENDES, E. G.; ALMEIDA, M. A.; TOYODA, C. Y. Inclusão escolar pela via da colaboração entre educação especial e educação regular, Educar em Revista, Curitiba: Editora UFPR, n. 41, p. 81-93. 2011.

MOURA, E. M.; SILVA, J. C. Reprovação Escolar: Discutindo mitos e realidade, Secretaria de Estado da Educação, Programa de Desenvolvimento Educacional - PDE, 2005.

OLIVA, D. V. A educação de pessoas com deficiência visual: inclusão escolar e preconceito. 2011. 246 f. Dissertação (Mestrado em Psicologia). Instituto de Psicologia, Universidade de São Paulo, São Paulo, 2011.

OLIVEIRA, C.; BISINOTO, E.; MARINHO-ARAÚJO, C. A relação família-escola: intersecções e desafios. Estudos de Psicologia, Campinas, vol. 27, n. 1, p. 99-108. 2010.

PATTO, M. H. S. A família pobre e a escola pública: anotações sobre um desencontro, Instituto de Psicologia - USP, São Paulo, n. 3, p. 107-121, 1992. 
POLÔNIA, A. C.; DESSEN, M. A. Em busca de uma compreensão das relações entre família e escola. Psicologia Escolare Educacional, vol. 9, n. 2, p. 303-312. 2005.

SHIMONO, S. O. Educação e trabalho: Caminhos da inclusão na perspectiva da pessoa com deficiência. 2008. 118 f. Dissertação (Mestrado em Educação). Faculdade de Educação, Universidade de São Paulo, São Paulo, 2008.

SILVA, N. A. P.; DESSEN, M. A. Deficiência Mental e Familia: Implicações para o desenvolvimento da criança. Psicologia: Teoria e Pesquisa, vol. 17, n. 2, p. 133-141, maiago. 2001.

SOUZA, A. A. et al. Evasão escolar no ensino médio: velhos ou novos dilemas? Vértices, Campos dos Goytacazes/RJ, v. 18, n. 1, p. 25-37, jan/abr. 2011.

SOUZA, A. P; JOSÉ FILHO, M. A importância da parceria entre a família e escola no desenvolvimento educacional, Revista Iberoamericana de Educación, Editora: Organización de Estados Iberoamericanos para la Educación, la Ciencia y la Cultura OEIJ, n. 44/7, 2008.

TOBIAS-MACHADO, M. et al., Achados Neuro-urológicos da síndrome de Williams: relato de caso, Arq. Neuropsiquiatr., vol. 56, n. 3B, p. 683-687. 1998. 


\section{Notas}

i Discentes do curso de Licenciatura em Educação Especial da Universidade Federal de São Carlos - UFSCar, CEP: 13565-905, São Carlos - SP, Brasil. e-mail: harume.muto@gmail.com, leomaximoemelo@yahoo.com.br ii Professora Adjunta do Departamento de Psicologia do Centro de Educação e Ciências Humanas $(\mathrm{CECH})$ da Universidade Federal de São Carlos - UFSCar, CEP 13565-905, São Carlos - SP, Brasil. e-mail: jappcampos@gmail.com .

iii São considerados alunos público-alvo da educação especial (PAEE) os alunos com deficiência, transtornos globais do desenvolvimento, e altas habilidades/ superdotação (BRASIL, 2008).

iv O Currículo é definido por Libâneo (2013) como um projeto pedagógico-curricular que concretiza o processo de planejamento de objetivos, diretrizes e ações do processo educativo a ser desenvolvido na escola, expressando a síntese das exigências sociais e legais do sistema de ensino e os propósitos e expectativas da comunidade escolar (p.126). É um instrumento que estabelece e cria objetivos; procedimentos; instrumentos de ensino e avaliação; modos de agir; estrutura, contextualiza e caracteriza a escola e a gestão; hábitos; valores; aspectos sociais, econômicos, culturais e geográfico; proposta de formação continuada; e proposta de trabalhos com os pais e comunidade. 